\title{
Transport, Social Equity and Capabilities in East Beijing
}

\section{Author names and affiliations:}

- Mengqiu Cao*

School of Architecture and Cities, University of Westminster, London, UK

Bartlett School of Planning, University College London, London, UK

- Robin Hickman

Bartlett School of Planning, University College London, London, UK

\section{Corresponding author:}

* Mengqiu Cao

E-mail addresses: m.cao@westminster.ac.uk / mengqiu.cao.13@ucl.ac.uk (M. Cao).

\begin{abstract}
This chapter utilises the Capabilities Approach to assess different levels of social equity in relation to transport provision in East Beijing. The aim of the analysis is to explore the different levels of social equity relative to gender, age, hukou, personal income and car ownership, specifically in terms of capabilities and functionings, that is, we investigate how the perceived opportunity to travel and access activities as well as actual travel differs across population groups. East Beijing, and in particular the district of Guomao, is used as a case study, to illustrate features of a relatively wealthy area with abundant transport resources. The research analysis shows that capabilities and functionings differ according to an individual's socioeconomic characteristics. In transport planning, in China and beyond, we would argue that transport-related social inequity has been largely overlooked in developing transport systems and is not considered to any significant extent in project appraisal.
\end{abstract}

Keywords: Transport; travel behavior; social equity; mobility; the Capabilities Approach; Beijing 


\section{INTRODUCTION}

Transport planning, both in China and internationally, has conventionally been focused on providing for increased levels of mobility, initially in terms of highway capacity for the private car, but increasingly with regard to infrastructure for public transport, walking and cycling. A significant problem has been that the appraisal and evaluation of projects has also focused on metrics of mobility, for example measuring the number of vehicle kilometres travelled, at the city or neighbourhood level. This has led to investment in projects that enhance levels of mobility, while relatively limited consideration is given to other important policy objectives, such as transport's contribution to social (and environmental) goals.

In the field of transport and urban planning, transport-related social equity has begun to attract the attention of researchers (Beyazit, 2011; Lucas, 2012; Pereira et al., 2017; Martens, 2017; Cao and Hickman, 2019a). Transport is fundamentally related to social equity in that it allows people to access a range of activities and participate in life. However, issues relating specifically to transport's impact on social equity, particularly in terms of fulfilling expectations and needs, and how this relates to individuals' actual activities, remain poorly understood (Ryan et al., 2015). This may partly be due to the complexity of these relationships and the difficulties involved in measuring, quantifying and comparing these issues. However, the imperative to develop more socially-equitable cities and lifestyles remains with us, and thus there is an urgent need for both theoretical and empirical research into transport and social equity.

This chapter utilises the Capabilities Approach (Sen, 1980, 2009; Nussbaum, 2003, 2011) to assess different levels of social equity in relation to transport provision in East Beijing. Nussbaum's 10 Central Human Capabilities $(2003,2011)$ are used to assess how capabilities and functionings might differ according to an individual's socio-demographic context. The aim of the analysis is to explore differences in levels of social equity relative to factors such as gender, age, hukou, personal income and car ownership. The key argument developed is that the real opportunities to travel and access a range of activities, as well as people's actual travel, differs across population groups.

The chapter is divided into five further sections. Section 2 provides a review of the literature on transport-related social equity in urban China. Section 3 discusses the Capabilities Approach and its potential application within the transport context. Section 4 offers an overview of the selected case study in East Beijing and explains the data and methodology used in the analysis. Section 5 presents the results of the modelling analysis and discusses the research findings. Finally, section 6 provides reflections on the theoretical and practical implications of the research. 


\section{TRANSPORT AND SOCIAL EQUITY IN CHINA}

In China, transport planning primarily aims to reduce congestion on the transport networks (Guo et al., 2011). Urban and regional economic development is a primary objective, and infrastructure investment is seen as important to achieving this (Chen and Vickerman, 2017). Transport planning approaches tend to encourage increased mobility and economic growth, with "economic efficiency" often being used as a key metric in economic appraisal; hence, social equity issues can easily be overlooked (Lucas, 2012; Hickman and Dean, 2018; Cuthill et al., 2019). There are, however, many important issues to be considered - including which population cohorts are able to use the transport networks; how participation in activities (employment, education, leisure) is affected by the transport and urban development that follows; and what impacts increased motorisation has on life in the city, including for those without access to a car and those spending increasing amounts of time in congested travelling conditions.

Social equity is an important policy goal in China. For example, the policy document "Building a Harmonious Society" (BHS) provides a key vision for the country's future socio-economic development, and was officially introduced by the former Chinese president $\mathrm{Hu}$ in 2004 at the 4th Plenum of the 16th Central Committee of the Communist Party of China (CPC), in Beijing, and constituted the central theme of the 17th National Congress of the CPC in 2007. One of the six key roles of BHS policy in relation to political philosophy is to ensure "justice and equality/justice as fairness", thus emphasising the aim of achieving and maintaining social equity in China. This point echoes one of Rawls' (2001: 42) key principles, namely "fair equality of opportunity", meaning that the human rights of all citizens should be protected and equal opportunities be given to all to acquire liberties through both tangible and intangible assets, especially in the case of disadvantaged groups within society.

These issues have only recently begun to be considered in China in the transport planning context. For example, Shi (2015) examines travel convenience and efficiency based on individuals' daily commutes, measuring accessibility, using a case study of Shanghai city centre. The study found that social equity-related individual accessibility levels are significantly associated with different sociodemographics, such as: age; whether people are incumbent residents or newcomers; whether they hold a driving licence or not; and residential location. At the meso-level, Zhao (2015) investigates commuting-related transport injustice in relation to the quality of urban life, comparing low, middle and high-income earners in Beijing. His research found that most low-income families experienced higher commuting burdens than the other two income cohorts, and that their daily commutes took longer than those of the high-income groups. Zhao and $\mathrm{Li}$ (2016) argue that spatial planning could play an effective role in reducing transport injustice if it was better integrated with transport and housing policies. Additionally, Zhao and Howden-Chapman (2010) investigate the impact of the existing hukou system 
for local urban residents and rural migrants, in terms of job accessibility and commuting, using Beijing as a case study. They found that residents with a local urban hukou had much greater levels of accessibility to jobs than migrants. At the macro-level, Ahmed et al. (2008) conduct a comparative study to assess social injustice in two international mega cities, Beijing and Karachi. They found that transport-related justice issues in both cities were caused mainly by inadequate transport infrastructure investment, exclusionary planning, growing motorisation, and uncontrolled increases in urbanisation. They reached a similar conclusion, namely that integrated land use and transport planning should be the focus of development, as car-oriented development and more technologically advanced transport systems were unlikely to offer many benefits, particularly to low-income cohorts and the urban poor. Hence, examining the social impacts of transport is a newly-emerging area of research in China, and this chapter aims to contribute to the debate.

\section{USING THE CAPABILITIES APPROACH IN THE TRANSPORT CONTEXT}

The analysis in this chapter uses the Capabilities Approach (CA) as a theoretical framework to examine travel behaviours and social equity. CA was developed by Amartya Sen $(1980,2009)$ to help examine the human and multi-dimensional elements of development, moving beyond the narrow focus on income growth. It has not been used in transport planning, with the exception of a few emerging papers that suggest CA might be well-suited to examining travel behaviours (Beyazit, 2011; Ryan et al., 2015; Mella-Lira and Hickman, 2017) and some initial emerging use of data to test the approach (Hickman et al., 2017; Cao and Hickman, 2019a, 2019b).

Sen describes CA as having: "an informational focus in judging and comparing overall individual advantages [...] judged in terms of opportunity rather than a specific 'design' for how a society should be organised" (Sen, 2009: 232) and explains that CA: "focuses on human life, and not just on some detached objects of convenience, such as incomes or commodities that a person may possess, which are often taken, especially in economic analysis, to be the main criteria of human success" (2009: 233). Hence CA can help to understand people's ability to achieve something beyond what they have already achieved (Sen, 2009). It might be the case that vulnerable people will need additional resources to help them reach the same or a similar level as an "average" person (Sen, 1985). CA can be seen as a refinement of Utilitarian equality (Bentham, 1879), which seeks to maximise the benefits for all; and of Rawlsian equality, which is focused on maximising the benefits for the leastadvantaged groups after basic equal rights have been secured in a society (Rawls, 1971). CA encompasses the following central concepts:

- Capabilities: the "alternative combinations of beings and doings that are feasible to achieve", that is, what real opportunities are available for people to do and be (Sen, 1999: 75). 
- Functionings: the "various things a person values being and doing"; hence realised functionings represent what a person actually does (Sen, 1999: 75).

We interpret this in the transport context as helping to assess the expectation to access different activities within particular contextual constraints (capabilities) relative to actual travel and participation in activities (realised functionings) (Hickman et al., 2017). Hence capability is the substantive freedom to achieve different activities and lifestyles. Both capabilities and realised functionings are likely to differ markedly by context and also by socio-demographic group, and it is the latter that we examine in this chapter.

Table 19.1 illustrates the central human capabilities, adapted from Nussbaum's categorisation (2003, 2011). The central human capabilities include factors such as life, health, bodily integrity, emotion and so on, representing social factors, at the individual level, that transport may contribute to. Each factor is illustrated with a typical indicator (for example, being able to not die prematurely) together with its more specific application(s) in the transport context (for example, being able to travel safely). Whilst there is debate over the range and coverage of capabilities and how particular indicators should be illustrated and applied in transport, we suggest these areas are a useful basis to examine the social impacts of different travel possibilities. They include issues such as experience, emotion, reason and affiliation, which are not usually included in social impact assessment.

An added dimension is that we consider both capabilities and realised functionings, and thus compare people's expectations relative to their actual travel. The analysis is based on the following type of survey questions designed to assess transport-related social equity in terms of capabilities and functionings, used by Cao and Hickman (2019a, 2019b): 


\begin{tabular}{|lll|}
\hline a. Capabilities & & $\begin{array}{l}\text { Your expected opportunities for travel } \\
\text { and activities } \\
\text { (i.e. your wishes/expectations) }\end{array}$ \\
& VS. & \\
b. Functionings & & $\begin{array}{l}\text { Your everyday travel and activities } \\
\text { (i.e. your current situation) }\end{array}$ \\
\hline
\end{tabular}

Example 1: ${ }^{1}$

Example: Within Beijing, I would be able to visit my family or meet up with

friends:

$$
\begin{array}{llllll}
0 & 1 & 2 & 3 & 4 & 5
\end{array}
$$

a. Ideally - if I could use

whatever form of transport I

wanted

b. In reality - based on the

N/A low high

availability of transport modes

on a day-to-day basis

Table 19.1 Nussbaum's central human capabilities and application in transport planning

\begin{tabular}{|c|c|c|}
\hline $\begin{array}{l}\text { Central Human } \\
\text { Capability } \\
\text { Category }\end{array}$ & $\begin{array}{l}\text { Indicator } \\
\text { Being able to: }\end{array}$ & $\begin{array}{l}\text { Application in Transport Planning } \\
\text { Being able to: }\end{array}$ \\
\hline 1. Life & Survive and not to die prematurely & $\begin{array}{l}\text { - Travel safely with minimal risk of } \\
\text { accidents } \\
\text { - Access food and clothes shopping }\end{array}$ \\
\hline 2. Bodily Health & $\begin{array}{l}\text { Live with a good standard of healthcare, adequate food } \\
\text { and drink, sleep, and shelter }\end{array}$ & $\begin{array}{l}\text { - Access daily activities } \\
\text { - Travel actively, such as by walking, } \\
\text { cycling and public transport } \\
\text { - Access a general practitioner (GP) or } \\
\text { hospital }\end{array}$ \\
\hline 3. Bodily Integrity & $\begin{array}{l}\text { Access mobility and to be protected against criminal } \\
\text { offence, injury, assault and threat }\end{array}$ & $\begin{array}{l}\text { - } \quad \text { Move from one place to another without } \\
\text { fear of injury, assault, or threat }\end{array}$ \\
\hline $\begin{array}{l}\text { 4. Senses, } \\
\text { Imagination, and } \\
\text { Thought }\end{array}$ & $\begin{array}{l}\text { Feel, understand, imagine, speak and think in a truly } \\
\text { humane way, while undertaking basic daily activities } \\
\text { (for example exercising freedom of choice regarding } \\
\text { religion, literature, and music, etc.) and work and live } \\
\text { without interruption by others; to be able to access } \\
\text { training and education }\end{array}$ & $\begin{array}{l}\text { - Access employment, education and } \\
\text { training opportunities } \\
\text { - Access cultural and entertainment } \\
\text { opportunities Being able to produce good } \\
\text { ideas, imagine and reflect on one's work } \\
\text { and daily life, including reading, listening } \\
\text { to music, and accessing Wi-Fi whilst } \\
\text { travelling }\end{array}$ \\
\hline
\end{tabular}




\begin{tabular}{|c|c|c|}
\hline 5. Emotions & $\begin{array}{l}\text { Rely on things and other people beyond ourselves; to } \\
\text { enjoy activities and participation; to love, grieve and } \\
\text { care for others }\end{array}$ & 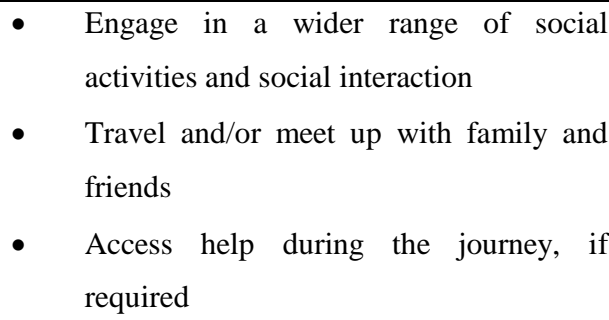 \\
\hline $\begin{array}{l}\text { 6. Practical } \\
\text { Reason }\end{array}$ & $\begin{array}{l}\text { Exercise freedom of religious and other beliefs } \\
\text { without punishment; to reflect and to be proud of } \\
\text { achievements gained in life }\end{array}$ & $\begin{array}{l}\text { - Use different means of transport without } \\
\text { experiencing any discrimination } \\
\text { - } \quad \text { Access a wide range of cultural activities }\end{array}$ \\
\hline 7. Affiliation & $\begin{array}{l}\text { Live equally and communicate with other people in a } \\
\text { society without any discrimination or unjust judgment } \\
\text { based upon differences in gender, race, ethnicity, } \\
\text { national origin, sexual orientation, and religion; } \\
\text { vulnerable groups are cared for by others }\end{array}$ & 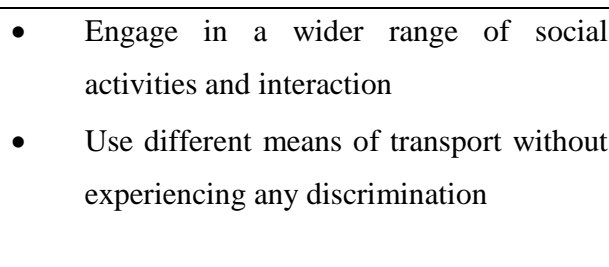 \\
\hline 8.Other Species & $\begin{array}{l}\text { Peacefully coexist with other species in the natural } \\
\text { world without destroying their living environment to } \\
\text { fulfil human demands }\end{array}$ & $\begin{array}{l}\text { - Use different modes of transport without } \\
\text { causing any adverse effects such as } \\
\text { environmental degradation and noise } \\
\text { pollution } \\
\text { - Use renewable and clean energy rather } \\
\text { than fossil fuels for travel }\end{array}$ \\
\hline 9.Play & Enjoy recreational activities, have fun, play and laugh & $\begin{array}{l}\text { - } \quad \text { Engage in a wide range of social activities } \\
\text { and interactions } \\
\text { - } \quad \text { Play and have fun }\end{array}$ \\
\hline $\begin{array}{l}\text { 10.Control Over } \\
\text { One's } \\
\text { Environment }\end{array}$ & $\begin{array}{l}\text { Have equal opportunities to access employment and } \\
\text { work with others; efforts and achievements within the } \\
\text { workplace are respected and recognised by others; to } \\
\text { have access to a home; to vote and be elected and } \\
\text { participate equally in politics and the governance of } \\
\text { people's lives }\end{array}$ & 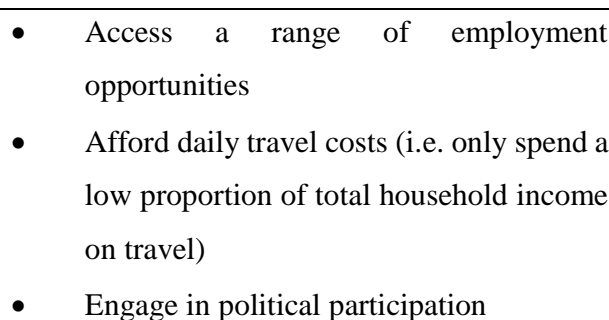 \\
\hline
\end{tabular}

Source: Cao and Hickman (2019b).

\section{CASE STUDY AND METHOD}

\subsection{Case Study Context}

East Beijing and, in particular, Guomao (the Central Business District (CBD) within Chaoyang District, adjacent to the Third Ring Road) is used as the case study. It was chosen to illustrate features of a relatively high-income neighbourhood. Guomao is a commercial area which had approximately 56,000 permanent residents, and 390,000 people working in its various businesses and commercial systems in 2016. Construction of the Chinese World Trade Centre (CWTC) began in Guomao in 1985, covering 
an area of 12 hectares. After five years of building, the landmark CWTC became the second largest World Trade Centre in the world, behind the original one in New York. Guomao subway station opened in 1999 and is located on Line One (Figure 19.1). In 1993, Guomao's flyover was built, forming another element of Chang'an Road's infrastructure. Although Guomao is a relatively wealthy area with abundant transport resources within Beijing, it still has distinct social groups (for example some residents do not use the resources due to certain barriers, which could restrict their daily travel activities within the neighbourhood, see Li and Zhao, 2018) living in the station catchment area.

Figure 19.1 Case Study of Guomao, Urban East Beijing

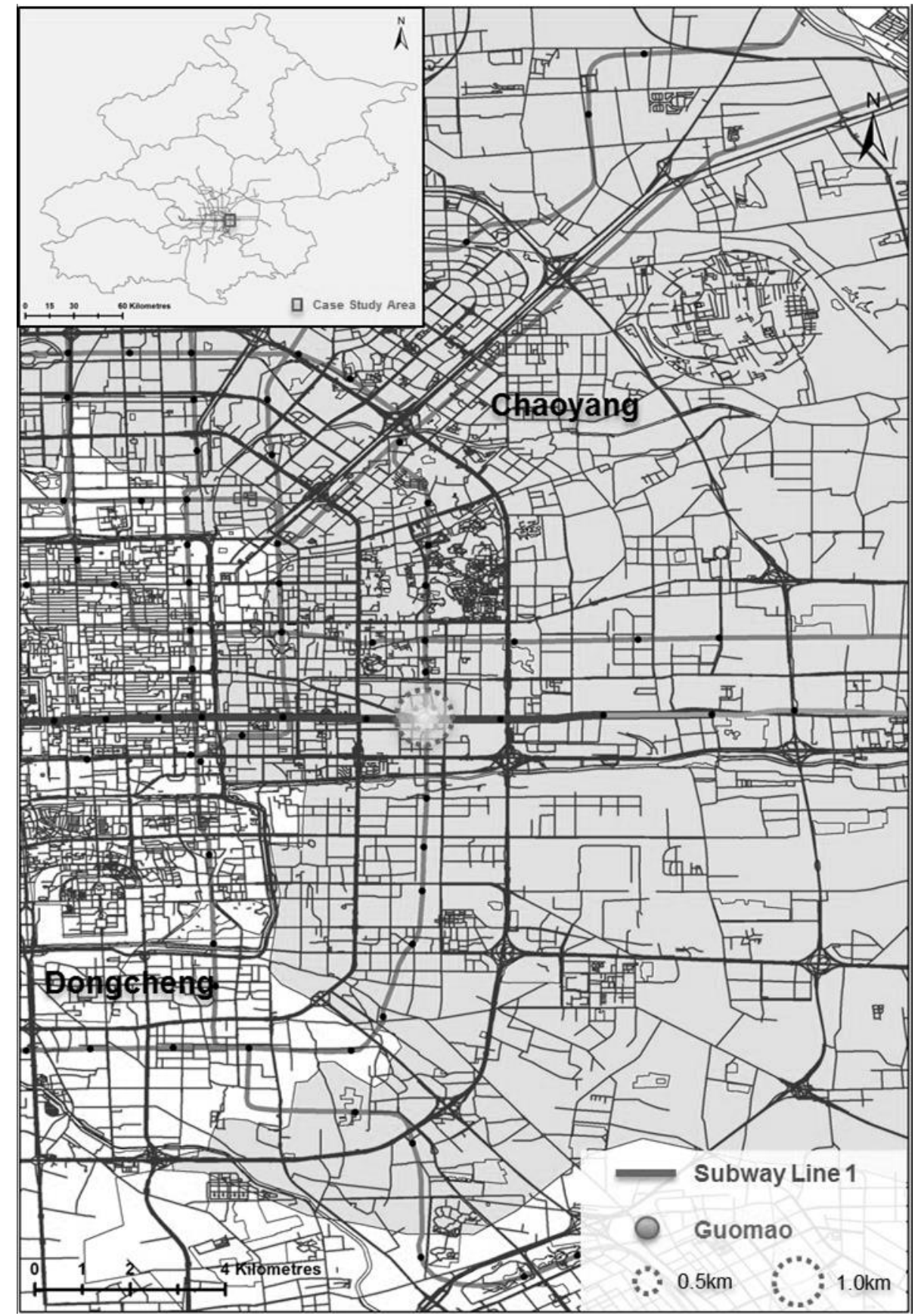

Source: The authors. 


\subsection{Data and Methods}

Face-to-face surveys were conducted with 846 residents in 2016 (Cao, 2019). A simple random sampling approach was used to select (Fink, 2003; Valliant et al., 2013) and interview participants who were walking either near the station or in the communities within the station catchment area. A systematic sampling approach was used to select households (Fink, 2003; Pfeffermann and Rao, 2009) and carry out personal interview surveys in the communities within the station catchment area. All the respondents lived in Guomao, within a $1 \mathrm{~km}$ radius of the station catchment area, and could access Line 1 of the subway (see RICS, 2002). The residents had a relatively similar levels of accessibility to the subway station, yet they chose to use or not use public transport in different ways. The survey elicited 790 valid responses, representing a sample of approximately 1.4 per cent of Guomao's population. Descriptions of the variables are provided in Table 19.2. Descriptive analysis of the responses is shown in Table 19.3.

Table 19.2 Descriptions of variables

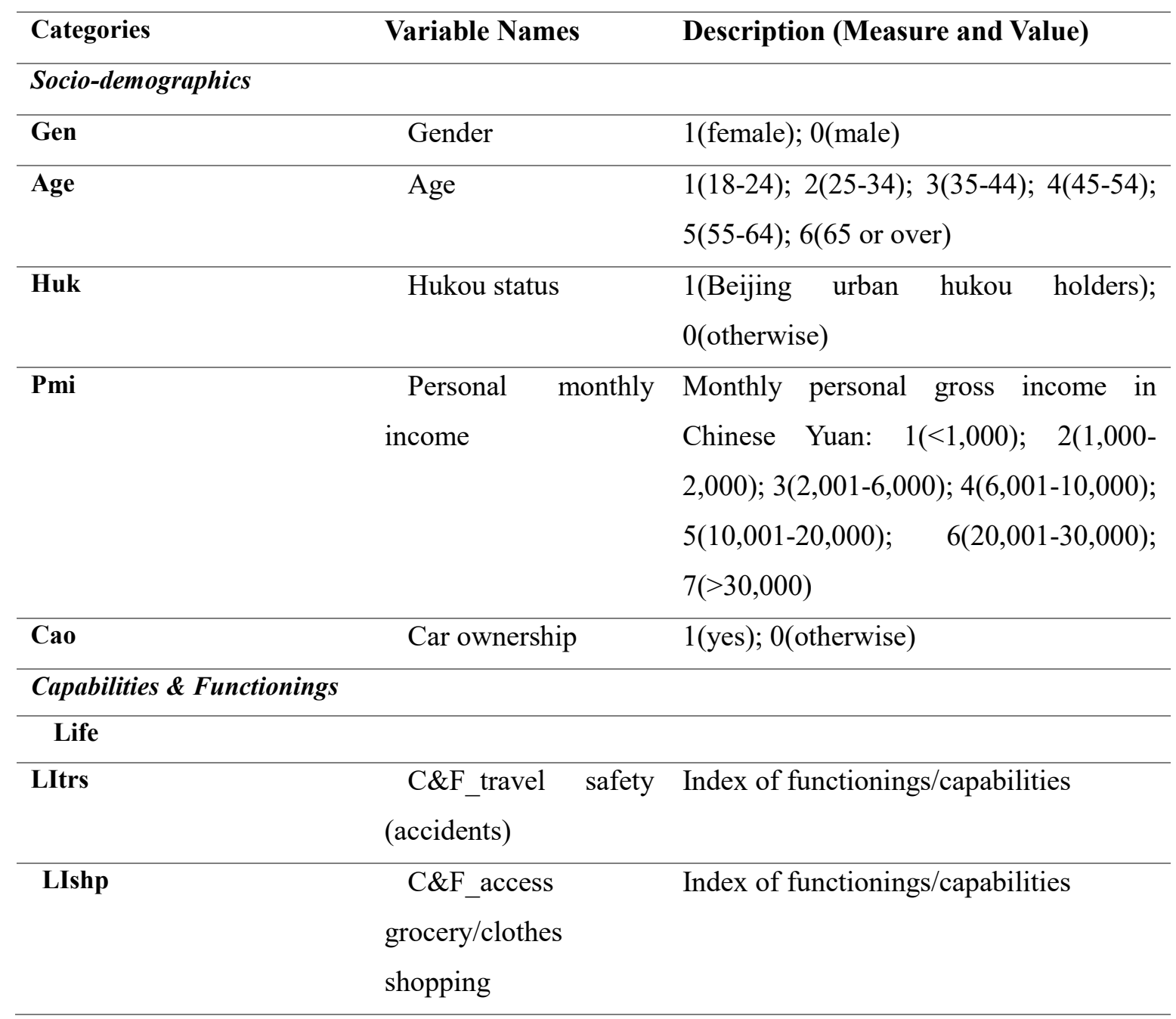




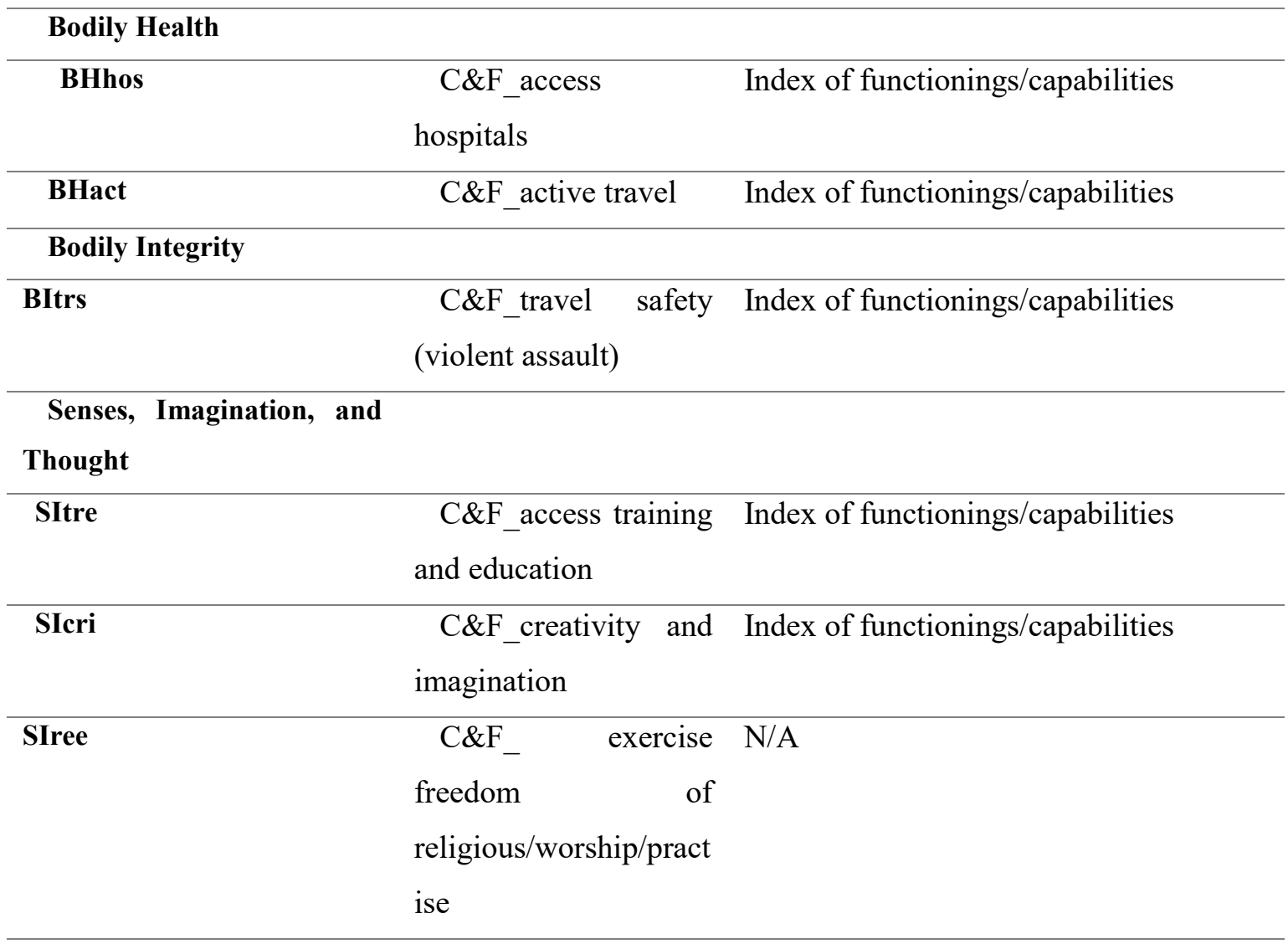

\section{Emotions}

EMtrv C\&F_travel and visit Index of functionings/capabilities family/friends

\begin{tabular}{lr}
\hline Practical Reason & C\&F_access cultural Index of functionings/capabilities \\
PRcua & activities \\
&
\end{tabular}

\section{Affiliation}

\begin{tabular}{lcc}
\hline AFreh & $\begin{array}{c}\text { C\&F_respect and get } \\
\text { help Index of functionings/capabilities }\end{array}$ \\
\hline Other Species & C\&F_against & Index of functionings/capabilities \\
OSend & $\begin{array}{l}\text { environmental } \\
\text { degradation }\end{array}$ \\
\hline Play & C\&F_leisure and Index of functionings/capabilities \\
\hline PLler & recreation & \\
&
\end{tabular}

\section{Control Over One's}

\section{Environment}

\begin{tabular}{lll}
\hline COwoo & C\&F_seek $\quad$ work Index of functionings/capabilities \\
\hline
\end{tabular}


opportunities

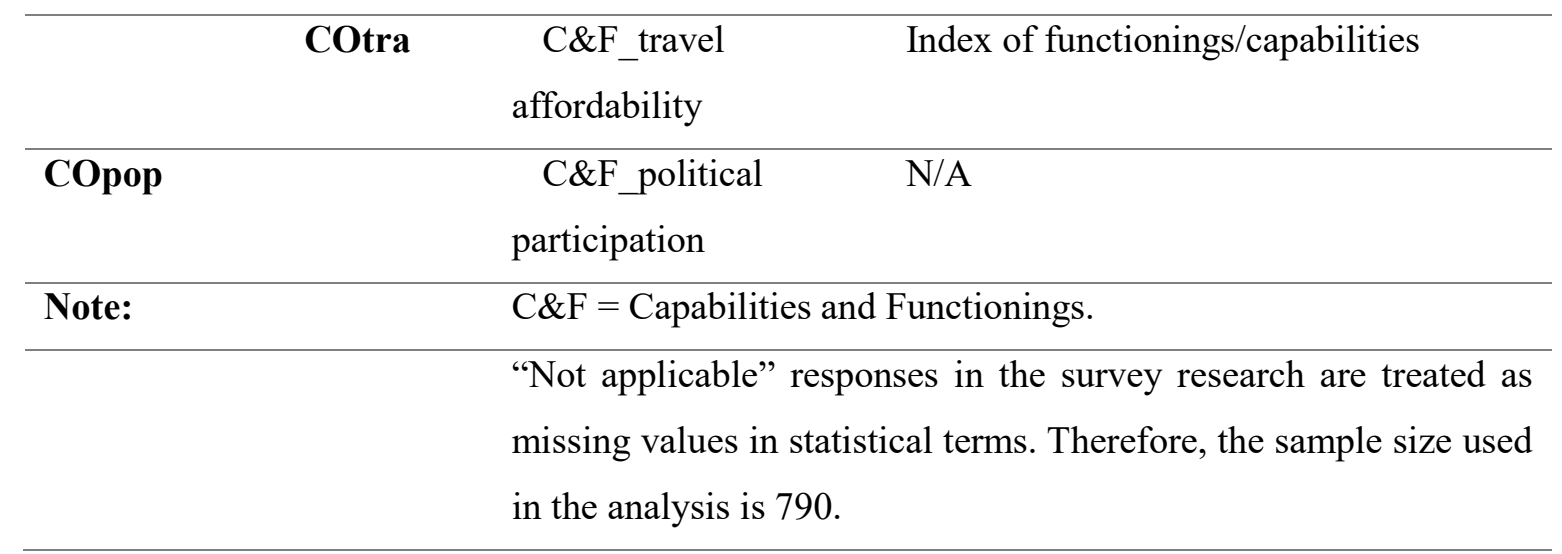

Source: The authors.

Table 19.3 Descriptive statistics

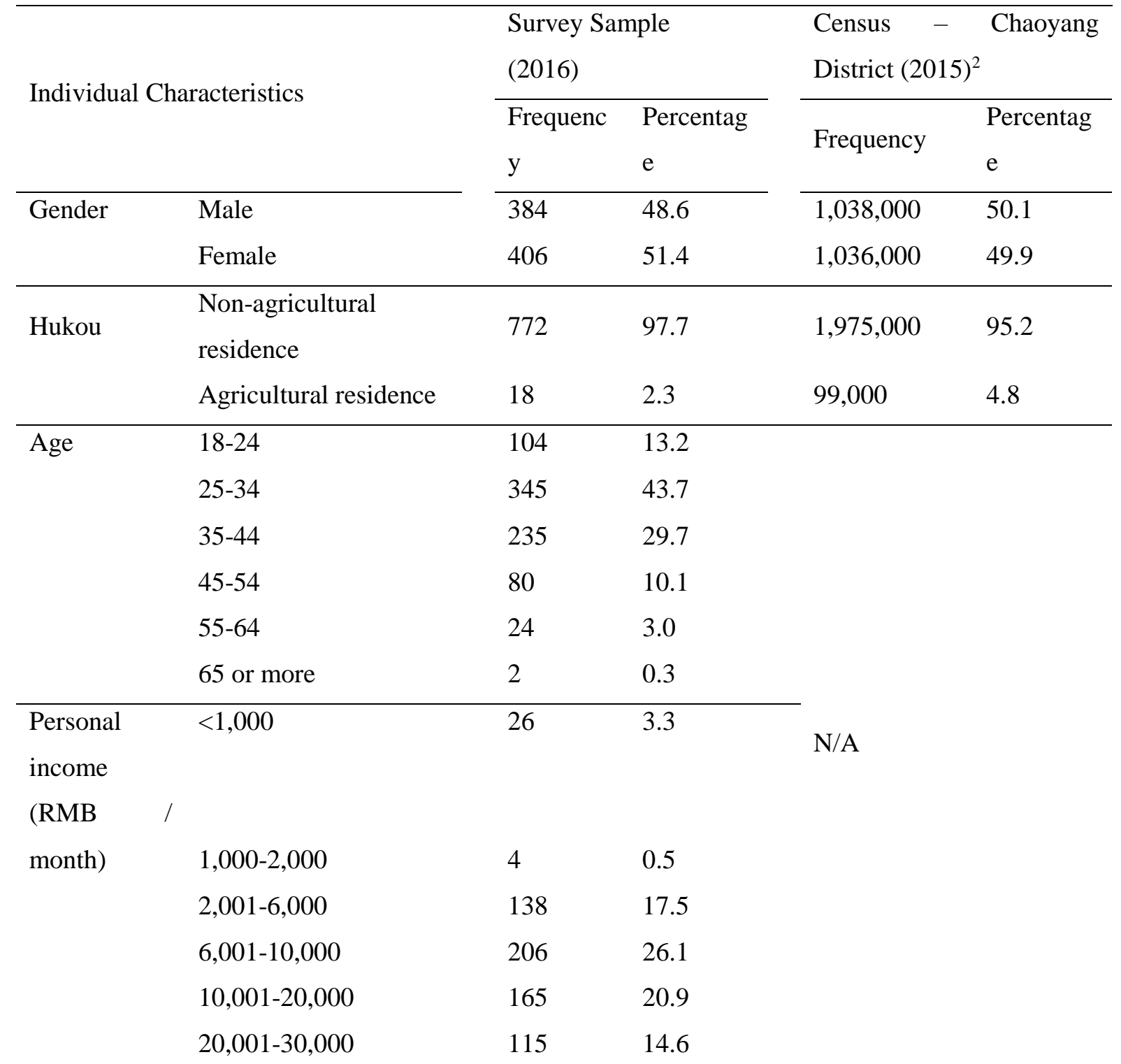




\begin{tabular}{llll}
\hline & $>30,000$ & 136 & 17.2 \\
\hline Car & & & \\
ownership & Yes & 589 & 74.6 \\
& No & 201 & 25.4 \\
\hline
\end{tabular}

Source: The authors.

In order to measure the differences between transport-related social equity for various potential groups of individuals, using capabilities and functionings, the basic test statistic employed is an F-test (see Blackorby et al., 1981; Foster and Shneyerov, 1996). This method is adapted from the study by Lorgelly et al. (2008), who used a similar approach to test their findings regarding inequalities in individual capabilities in order to understand the patterns and causes of enduring poor health of various groups among individuals in Glasgow. In the transport and social equity context, it is assumed that the levels of capabilities, functionings and/or the gap between them (which are all representations of "travel equity"), and the higher the value of the variability in the numerator of the F-statistic by population group (see Equation 19.1). Hence, if the scores for functionings and capabilities are similar, and so the difference between them is small, then this represents an equitable situation.

$F$ value $=\frac{\sum_{i=1}^{\mu} n_{i}\left(\bar{Y}_{i}-\bar{Y}\right)^{2} /(\mu-1)}{\sum_{i=1}^{\mu} \sum_{j=1}^{n_{i}} n_{i}\left(Y_{i j}-\bar{Y}_{i}\right)^{2} / v}$

Where:

- $\bar{Y}_{i:}$ the sample mean in the $\mathrm{i}^{\text {th }}$ group

- $n_{i}$ : the number of observations in the $\mathrm{i}^{\text {th }}$ group

- $\bar{Y}$ : the overall mean of the sample size

$-\mu$ : the number of groups

- $Y_{i j}$ : the $\mathrm{j}^{\text {th }}$ observation in the $\mathrm{i}^{\text {th }}$ out of $\mu$ groups

- $n$ : the overall sample size

$-v$ : degrees of freedom under the null hypothesis (i.e. $\mathrm{n}-\mu$ )

\section{MODELLING RESULTS AND COMMENTARY}

The key issue we examine is whether capabilities and functionings can demonstrate differences across socio-demographic groups, even within a relatively wealthy neighbourhood, such as Guomao, having abundant transport resources and a wide array of destination choices. Although, none of the respondents have poor access to public transport, there are still a number of barriers to using it (and hence the 
activities that it helps individuals to access), such as income, preference for using private cars, location of employment, retail and leisure facilities, and so on. In other words, the existing transport systems and services may not meet the mobility needs and abilities of the individuals and groups in question (this is also known as vertical equity), even though they have similar horizontal equity (i.e. fair and egalitarian access) (see Di Ciommo and Shiftan, 2017; Litman, 2018).

Five social equity groupings are taken into account in relation to transport: gender; age; hukou; income; and car ownership. Given the large number of comparative analyses which would result from Nussbaum's ten categories, five general groups are used, which are measured by 14 indicators of capabilities and functionings, respectively. Table 19.4 shows the summary test statistics. Significant findings regarding differences are marked with asterisks $(*)$.

Focusing on gender differences (column 2 of Table 19.4), it is found that females appear to have higher levels than males for both capabilities and functionings, particularly in relation to those activities which traditionally tend to be associated with women, such as "accessing grocery and clothes shopping"; "visiting family and friends"; "accessing cultural activities"; and "showing more respect to each other and being able to get help during the journey if needed". Robeyns (2002) also found that most males are less likely to meet up with their friends frequently, and are also less inclined to seek help from others than their female counterparts. In addition, the finding that shopping remains primarily a gendered activity, was in agreement with Dholakia (1999), whose survey results showed that females still predominantly take responsibility for household grocery shopping, although other factors such as marital status, age, and education also play a role. For instance, among the younger generation, and particularly in the case of married couples, men and women tend to take more equal responsibility for grocery shopping. However, it should be noted that, if travel equity is taken into account, women are still more likely to have larger gaps between capability and functioning scores than men, for activities such as "accessing training and education"; "travel safety (accidents and violent assault)"; and "travel affordability". Hence, women are still more likely to be perceived as vulnerable groups who face more contextual constraints than males, at least to an extent (Hamilton and Jenkins, 2000; Shin, 2011).

Column 3 considers the relationship between age and individual capabilities and functionings. It shows that there are statistically significant relationships between age groups and "accessing grocery and clothes shopping"; "accessing doctors"; "making active travel choices"; "creativity and imagination"; "visiting family and friends"; "showing more respect to each other and being able to get help during the journey if needed"; and being "against environmental degradation", in terms of capabilities but not functionings. This suggests that people generally tend to have higher levels of expectations to carry out the aforementioned activities. However, the findings also show that there are no significant differences between age groups in terms of fulfilling their expectations based on the actual availability of various transport modes on a day-to-day basis, that is, realised functionings. If this finding is considered in more depth, it can be seen that people aged over 45 generally have a greater 
need to access hospitals than the younger generations. However, the findings also show that both groups have very similar levels of functionings in terms of implementing the aforementioned activities, meaning that it may not be possible for older people to actually fulfil their needs. Thus, the analysis implies that there are significant equity issues between different age groups, particularly between the young and old. In other words, the younger generation appear to enjoy better access to healthcare and active travel than the older generation in the Guomao area.

The hukou system is considered a key indicator when measuring mobility in China (Zhao and Howden-Chapman, 2010). In terms of finding employment or being able to travel to interviews, the results show that there is a statistically significant difference between local hukou holders and migrant workers (column 4). More specifically, it was found that most migrant workers have higher levels of job-seeking expectations than local hukou holders, although both groups have very similar levels of functionings in terms of "seeking work opportunities". To some extent, this suggests that there are significant equity issues between local hukou holders and migrant workers in the Guomao area. Although Chinese law seeks to ensure that everyone has equal opportunities to access employment and job interviews, regardless of the hukou system, it appears that migrant workers are still more likely to experience unequal treatment than local hukou holders when seeking employment.

The analyses of the differences between income groups, based on respondents' personal monthly incomes during the past 12 months (column 5), shows that most categories display highly statistically significant differences, including for life, bodily health, emotions and reasoning. This is not surprising, as Sen (1973), and many others, argue that the extent and importance of inequality generally varies across different income distributions. If travel equity is also considered, those on low personal incomes report a much larger travel inequity gap than respondents with high personal incomes. This suggests that people on lower incomes are more likely to experience travel constraints relative to what they would like to achieve.

With regards to car ownership, only two of the functionings categories have statistically significant differences (column 6). This implies that owning a car has little effect on the capabilities and functionings of residents living in Guomao. This can be explained by Guomao being in the CBD, and being one of the wealthiest neighbourhoods in Beijing with excellent infrastructure systems and convenient, high quality, public transport. Residents are therefore able to access key daily life activities relatively easily without needing a car. It can hence be argued that designing the built environment to support public transport usage can help mitigate the issues caused by transport-related social inequity. Access to public transport (and cycling and walking) is much more open to all than travelling by private car. 
Table 19.4 Summary test statistics (F tests) for differences in individual social equity in transport (i.e. capabilities and functionings) by gender, age, hukou, income, and car ownership in Guomao, Beijing $(\mathrm{n}=790)$

\begin{tabular}{llllll}
\hline Capabilities \& Functionings & Gender & Age & Hukou & $\begin{array}{l}\text { Personal } \\
\text { Income }\end{array}$ & $\begin{array}{l}\text { Car } \\
\text { Ownership }\end{array}$ \\
\hline Life & & & & & \\
C_travel safety (accidents) & $6.104^{*}$ & $7.803^{* * *}$ & $13.298^{* * *}$ & $19.152^{* * *}$ & $8.593^{* *}$ \\
$\begin{array}{l}\text { F_travel safety (accidents) } \\
\text { C_access grocery/clothes }\end{array}$ & 0.075 & $2.928^{*}$ & 1.954 & 1.331 & 0.002 \\
$\begin{array}{l}\text { shopping } \\
\text { F_access grocery/clothes }\end{array}$ & $18.122^{* * *}$ & $2.795^{*}$ & 0.073 & $15.655^{* * *}$ & 3.574 \\
shopping & $18.356^{* * *}$ & 1.532 & 2.763 & 1.645 & 0.001 \\
\hline $\begin{array}{l}\text { Bodily Health } \\
\text { C_access hospitals }\end{array}$ & $13.856^{* * *}$ & $2.991^{*}$ & 0.435 & $14.582^{* * *}$ & 0.753 \\
$\begin{array}{l}\text { F_access hospitals } \\
\text { C_active travel }\end{array}$ & $13.122^{* * *}$ & 1.310 & 1.944 & $3.040^{* *}$ & 0.091 \\
F_active travel & $12.325^{* * *}$ & $7.690^{* * *}$ & $5.719^{*}$ & $38.497^{* * *}$ & $9.979^{* *}$ \\
\hline Bodily Integrity & $4.472^{*}$ & 1.555 & $3.869^{*}$ & $6.124^{* * *}$ & 0.219 \\
C_travel safety (violent & & & & & \\
assault) & 2.827 & $4.220^{* * *}$ & $18.238^{* * *}$ & $14.297^{* * *}$ & $13.167^{* * *}$ \\
F_travel safety (violent & & & & & \\
assault) & 1.659 & 1.921 & 0.694 & 1.111 & $5.119^{*}$ \\
\hline Senses, Imaginaton & & & & & \\
\hline
\end{tabular}

\section{Senses, Imagination \&}

\section{Thought}

C_access training and

education

$11.538^{* * *} \quad 1.773 \quad 2.173 \quad 13.951 * * * \quad 0.778$

F_access training and

education

4.690* $\quad 1.002 \quad 0.344 \quad 6.839 * * * \quad 2.681$

C_creativity and imagination

$18.753 * * *$

$6.971 * * * \quad 9.265^{* *}$

$26.757 * * * \quad 6.713^{* *}$

F_creativity and imagination

2.942

0.503

1.272

$11.233^{* * *} \quad 0.487$

C_religious exercise

N/A

F_religious exercise

N/A

\section{Emotions}

C_travel and visit

$18.536^{* * *} \quad 2.572^{*} \quad 2.047$

$19.406^{* * *} \quad 2.122$ 
family/friends

F_travel and visit

family/friends

$\begin{array}{lllll}10.430 * * * & 1.869 & 3.122 & 9.560 * * * & 0.369\end{array}$

\begin{tabular}{llllll}
\hline Practical Reason & & & & & \\
C_access cultural activities & $13.371^{* * *}$ & 0.568 & 2.094 & $11.929^{* * *}$ & 0.077 \\
F_access cultural activities & $7.653^{* *}$ & $4.557^{* * *}$ & 0.355 & $3.965^{* * *}$ & 0.356 \\
\hline Affiliation & & & & & \\
C_respect and get help & $34.120^{* * *}$ & $8.521^{* * *}$ & $10.721^{* * *}$ & $33.054^{* * *}$ & $15.787^{* * *}$ \\
F_respect and get help & $18.476^{* * *}$ & 1.471 & 0.036 & $3.019^{* *}$ & 0.488 \\
\hline Other Species & & & & & \\
C_against environmental & & & & & \\
degradation & $7.145^{* *}$ & $8.110^{* * *}$ & $7.647^{* *}$ & $33.491^{* * *}$ & $5.596^{*}$ \\
F_against environmental & & & & & \\
degradation & 1.879 & 1.623 & 0.096 & $6.414^{* * *}$ & 2.265 \\
\hline Play & & & & & \\
C_leisure and recreation & 3.565 & 1.447 & $4.548^{*}$ & $9.684^{* * *}$ & 1.971 \\
F_leisure and recreation & 1.144 & 1.782 & $5.160^{*}$ & 1.374 & 0.387 \\
\hline Control Over One's & & & & & \\
Environment & & & & & \\
C_seek work opportunities & $5.313^{*}$ & 1.074 & $5.612^{*}$ & $10.745^{* * *}$ & 1.898 \\
F_seek work opportunities & $9.253^{* *}$ & $2.294^{*}$ & 1.101 & 1.307 & 0.342 \\
C_travel affordability & $14.186^{* * *}$ & 2.056 & 0.177 & $4.452^{* * *}$ & 0.159 \\
F_travel affordability & 0.938 & $4.242^{* * *}$ & $4.231^{*}$ & $2.446^{*}$ & $5.640^{*}$ \\
C_political participation & $\mathrm{N} / \mathrm{A}$ & & & & \\
F_political participation & $\mathrm{N} / \mathrm{A}$ & & & & \\
\hline Note: *p $<0.05, * * \mathrm{p}<0.01, * * * \mathrm{p}<0.001$. & & & & \\
\hline & & & & & \\
\hline
\end{tabular}

Source: The authors.

\section{CONCLUSIONS}

This chapter has explored the implications of transport-related social inequity, at the individual level, for residents who live in the subway station catchment area of Guomao, East Beijing, using the CA as a theoretical framework. The differences between capabilities and functionings across various sociodemographic categories have been analysed, to enable social equity within the transport planning context to be measured, quantified and compared. 
The context-specific analysis from the case study suggests that there are gender differences in transport-related social equity and these can be seen in relation to the spatial range of non-work travel activities. Previous research has emphasised how the hukou system constitutes a key barrier to social equity, limiting the range of opportunities available to migrants without a local urban hukou in Beijing (Zhao and Howden-Chapman, 2010). The results of this research are also in line with these findings, suggesting there are significant differences in social equity in terms of hukou. In addition, income plays a vital role in relation to individuals' use of, and expectations regarding, transport and is associated with inequality. People with higher personal incomes generally have much higher levels of both capabilities and functionings than lower income groups. Although conventional Gini coefficients have been used to measure the level of social inequity in contemporary society, the interrelationships between income disparity and transport interventions have been difficult to measure using income metrics. Further research could therefore seek to analyse differences across capabilities and functionings, and perhaps to develop a transport equity-related Gini coefficient index, to show the distribution of capabilities and functionings by area. This type of indicator could become important in assessing the impacts of transport projects and transport systems on social equity.

There are a number of further conclusions that can be drawn from the analysis, which contribute to the existing literature in three ways. First, the appraisal and evaluation of transport projects needs to include wide-ranging metrics that extend beyond the usual mobility metrics and cost-benefit analysis which focuses on economic efficiency. This should include social indicators, which reflect varied issues, including life, bodily health, emotion and reasoning, and so on. All of these could become important objectives for transport investment. Second, most of the existing literature on social equity tends to advocate and use accessibility as the key indicator with which to measure justice in a transport context (Martens, 2017). This represents a significant progression from using mobility metrics (such as number of vehicle kilometres travelled). However, people's potential travel expectations and actual travel have not been considered, and there is likely to be a difference between these - individuals may not always make use of the accessibility on offer due to various barriers. Therefore, we argue that investigating equity within the transport sector should not focus solely on people's current situation or everyday travel experiences (represented by "functionings"). It should also take into account expected travel activities or potential expectations (represented by "capabilities") and the context that frames these. This will lead transport planners to think beyond infrastructure provision, and also to consider the reasons, barriers and facilitators for people to use good accessibility, including the wider policy measures which may need to be implemented. Examples might include: reducing the cost of public transport; improving information; planning cities in a way that allows public transport usage; encouraging female participation in the workforce; and raising education and skill levels across different population cohorts. All of these can help to reduce levels of transport-related inequity alongside infrastructure provision. Many of these issues are beyond the usual remit of the transport 
planner. Third, the quantification and application of CA allows us to move beyond the abstract in thinking about social development. Utilising Nussbaum's Central Human Capabilities enables impacts which often seem ambiguous to be quantified. This approach can, of course, be developed, perhaps to include a different range of scoring, different topics, and different analytical techniques, including the use of qualitative interviews. It is suggested that CA can be applied as an important conceptual framework within transport planning.

In transport planning, both in the Chinese context and beyond, we would argue that transportrelated social inequity has been largely overlooked in analysis, and is not considered to any significant extent in project appraisal. This is out of step with wider national policy objectives in China which call for greater levels of social equity in support of a harmonious society. As part of this framework, it will be important to consider what an individual, particular population cohorts, and society as a whole, are able to do and to be. This "substantive freedom" (Sen, 1999: 18) - representing the expansion of capabilities to allow people to live the kind of lives they wish to lead - can become a key goal for public policy, and should be an integral part of the objectives for transport planning.

\section{ACKNOWLEDGEMENTS}

The authors would like to extend their appreciation to the British Council and Newton Fund Institutional Links Programme, Sustainable Cities and Resilient Transport Project (University of Oxford, UCL, Clean Air Asia, and De la Salle University, Manila, 2015-17) for partly assisting with funding for this research. Thanks to Dr Iqbal Hamiduddin; Dr Tingting Lu; and Dr Kate Tkacova for their suggestions. We would also like to thank the editor, Dr Chia-Lin Chen, and the two anonymous reviewers for all their insightful comments and suggestions on the initial manuscript. Thanks also to Dr Karel Martens; Dr Miriam Ricci; and Professor David Lagnado for sharing their ideas on this topic. The travel equity data used in this study came from a survey conducted in 2016 and the data was collected with the assistance of: the UCL team; Dr Zijia Wang and his team from Beijing Jiaotong University; Yue Qiu, Chen Chen and their team from Beijing International Studies University; Steven Zhang and his team from Ipsos; and Chao Du and her team from Chinese Academy of Sciences, and so on. The responsibility for all analysis, interpretation and conclusions drawn from the data lies entirely with the authors.

\section{NOTES}

${ }^{1}$ Example 1 consists of LIshp, BHhos, SItre, SIree, EMtry, PRcua, PLler, COwoo, and COpop (see 
Table 19.2).

${ }^{2}$ Source: Beijing Municipal Bureau of Statistics (2016). 


\section{REFERENCES}

Ahmed, Q.I., Lu, H. and Ye, Y. (2008). Urban Transportation and Equity: A Case Study of Beijing and Karachi. Transportation Research Part A, 42(1), pp. 125-139.

Beijing Municipal Bureau of Statistics (BMBS) (2016). Beijing Statistical Year Book. Beijing: China Statistics Press.

Bentham, J. (1879). An Introduction to the Principles of Morals and Legislation. New York: Dover Publications [reprinted 2007].

Beyazit, E. (2011). Evaluating Social Justice in Transport: Lessons to be Learned from the Capability Approach. Transport Reviews, 31(1), pp. 117-134.

Blackorby, C., Donaldson, D. and Auersperg, M. (1981). A New Procedure for the Measurement of Inequality within and among Population Subgroups. Canadian Journal of Economics, 4, pp. 665-685.

Cao, M. (2019). Exploring the Relation between Transport and Social Equity: Empirical Evidence from London and Beijing. Unpublished $\mathrm{PhD}$ thesis, London, UCL.

Cao, M. and Hickman, R. (2019a). Understanding Travel and Differential Capabilities and Functionings in Beijing. Transport Policy, 83, pp. 46-56.

Cao, M. and Hickman, R. (2019b). Urban Transport and Social Inequities in Neighbourhoods near Underground Stations in Greater London. Transportation Planning and Technology, 42(5), pp. 419-441.

Chen, C-L. and Vickerman, R. (2017). Can Transport Infrastructure Change Regions' Economic Fortunes? Some Evidence from Europe and China. Regional Studies, 51(1), pp. 144-160.

Cuthill, N. et al. (2019). The Association between Urban Public Transport Infrastructure and Social Equity and Spatial Accessibility within the Urban Environment: An Investigation of Tramlink in London. Sustainability, 11(5), p. 1229.

Dholakia, R. (1999). Going Shopping: Key Determinants of Shopping Behaviours and Motivations. International Journal of Retail and Distribution Management, 27(4), pp. $154-165$.

Di Ciommo, F. and Shiftan, Y. (2017). Transport Equity Analysis. Transport Reviews, 37(2), pp. 139-151.

Fink, A. (2003). How to Sample in Surveys. London: Sage Publications.

Foster, J. and Shneyerov, A. (1996). Path Independent Inequality Measures. Vanderbilt 
University: Department of Economics.

Guo, J., Liu, Y. and Yu, L. (2011). Traffic Congestion in Large Metropolitan Areas in China. Urban Transport of China, 9(2), pp. 8-14 (in Chinese).

Hamilton, K. and Jenkins, L. (2000). A Gender Audit for Public Transport: A New Policy Tool in the Tackling of Social Exclusion. Urban Studies, 37(10), pp. 1793-1800.

Hickman, R., Cao, M., Mella-Lira, B., Fillone, A. and Biona, J.B. (2017). Understanding Capabilities, Functionings and Travel in High and Low Income Neighbourhoods in Manila. Social Inclusion, 5(4), pp. 161-174.

Hickman, R. and Dean, M. (2018). Incomplete Cost Incomplete Benefit Analysis in Transport Appraisal. Transport Reviews, 38(6), pp. 689-709.

Li, S. and Zhao, P. (2018). Restrained Mobility in a High-accessible and Migrant-rich Area in Downtown Beijing. European Transport Research Review, 10(4), pp. 1-17.

Litman T. (2018). Evaluating Transportation Equity: Guidance for Incorporating Distributional Impacts in Transportation Planning (revised edition). http://www.vtpi.org/equity.pdf (accessed 3 November 2018).

Lorgelly, P.K., Lorimer, K., Fenwick, E. and Briggs, A.H. (2008). The Capability Approach: Developing an Instrument for Evaluating Public Health Interventions. University of Glasgow: Section of Public Health and Health Policy.

Lucas, K. (2012). Transport and Social Exclusion: Where Are We Now?. Transport Policy, 20, pp. 105-113.

Martens, K. (2017). Transport Justice: Designing fair Transportation Systems. New York: Routledge.

Mella-Lira, B. and Hickman, R. (2017). Using the Capability Approach as An Instrument for Assessing the Social Impact of Transport Projects. Working Paper, London, UCL.

Nussbaum, M. (2003). Capabilities as Fundamental Entitlements: Sen and Social Justice. Feminist Economics, 9(2-3), pp. 33-59.

Nussbaum, M. (2011). Creating Capabilities: The Human Development Approach. Cambridge: Belknap.

Pereira, R., Schwanen, T. and Banister, D. (2017). Distributive Justice and Equity in Transportation. Transport Reviews, 37(2), pp. 170-191.

Pfeffermann, D. and Rao, C.R. (2009). Handbook of Statistics 29A - Sample Surveys: Design, Methods and Applications. Oxford: North Holland.

Rawls, J. (1971). Justice as Fairness. Cambridge, MA: The Belknap Press of Harvard 
University Press.

Rawls, J. (2001). Justice as Fairness: A Restatement. Cambridge, MA: The Belknap Press of Harvard University Press.

RICS (2002). Land Value and Public Transport: Stage 1 - Summary of Findings. RICS Policy Unit, October.

Robeyns, I. (2002). Gender Inequality: A Capability Perspective. Doctoral dissertation, Cambridge University, UK.

Ryan, J., Wretstrand, A. and Schmidt, S.M. (2015). Exploring Public Transport as an Element of Older Persons' Mobility: A Capability Approach Perspective. Journal of Transport Geography, 48, pp. 105-114.

Sen, A. (1973). On Economic Inequality. Oxford: Clarendon Press.

Sen, A. (1980). Equality of What? In: McMurrin S. Tanner (ed.), Lectures on Human Values, Volume 1. Cambridge: Cambridge University Press. The Tanner Lecture on Human Values, https://scholar.harvard.edu/sen/publications/equality-what (accessed 24 October 2019).

Sen, A. (1985). Commodities and Capabilities. Amsterdam: North-Holland.

Sen, A. (1999). Development as Freedom. Oxford: Oxford University Press.

Sen, A. (2009). The Idea of Justice. London: Penguin Books.

Shi, C. (2015). Social Equity and Impact Evaluation Based on Urban Transport Accessibility Quantitative Measure: Case Study of Shanghai City Centre. Shanghai: Tongji University.

Shin, H. (2011). Spatial Capability for Understanding Gendered Mobility for Korean Christian Immigrant Women in Los Angeles. Urban Studies, 48(11), pp. 2355-2373.

Valliant, R., Dever, J.A. and Kreuter, F. (2013). Practical Tools for Designing and Weighting Survey Samples. London: Springer.

Zhao, P. (2015). The Determinants of the Commuting Burden of Low-income Workers: Evidence from Beijing. Environment and Planning A, 47, pp. 1736-1755.

Zhao, P. and Howden-Chapman, P. (2010). Social Inequalities in Mobility: the Impact of the Hukou System on Migrants' Job Accessibility and Commuting Costs in Beijing. International Development Planning Review, 32(3-4), pp. 363-384.

Zhao, P. and Li, S. (2016). Restraining Transport Inequality in Growing Cities: Can Spatial Planning Play a Role? International Journal of Sustainable Transportation, 10(10), pp. 947-959. 